\title{
Predictors of Screening for Breast, Cervical, Colorectal, and Prostatic Cancer Among Community-Based Primary Care Practices
}

\author{
Mack T. Ruffin IV, MD, MPH, Daniel W. Gorenflo, PbD, and Brent Woodman
}

Background: As we enter the year 2000, it is worth looking at whether primary care practices are reaching the goals established in Healtby People 2000 for breast, cervical, colorectal, and prostatic cancer screening. The objectives of this study were (1) to determine the current rates of cancer screening; and (2) to determine which factors predict completion of a single screening test, of all tests for each cancer, and of all procedures for age and sex.

Metbods: Medical records of 200 eligible patients (100 men and 100 women) from each of 24 community-based primary care practices were abstracted for cancer-screening events.

Results: We audited 5125 charts. A Papanicolaou smear was documented for $63.8 \%$ of women with an intact cervix within 3 years of the audit.. We found that $\mathbf{4 6 . 8 \%}$ of women had documentation of ever having a discussion of breast self-examination. For breast cancer screening, $41.8 \%$ of the women had a clinical breast examination within 1 year, $48.2 \%$ aged 40 to 49 years had a mammogram within 2 years, and 38.5\% aged 50 years and older had a mammogram within 1 year. Only $29 \%$ of women aged 40 to 49 years and $17 \%$ of women 50 years and older were current for all breast cancer-screening tests. Among patients 50 years and older, 33\% of men and $38 \%$ of women had a digital rectal examination within 1 year, $26 \%$ of men and $28 \%$ of women had a fecal occult blood test within 1 year, and $22 \%$ of men and $16.8 \%$ of women had a flexible sigmoidoscopy within 5 years. Of all men $28.7 \%$ had a prostate-specific antigen test within 1 year. Completion of all tests relevant for age and sex were documented for $8.6 \%$ of women aged 40 to 49 years, $3 \%$ of women 50 years and older, and $5 \%$ of men 50 years and older. The single most significant predictor of documented cancer screening was a health maintenance visit.

Conclusions: This sample of primary care clinicians has not reached the goals set in Healthy People 2000 for cancer screening. Interventions aimed at increasing the percentage of patients who schedule a health maintenance visit could serve to increase cancer screening and help us reach goals set for the year 2010. (J Am Board Fam Pract 2000;13:1-10.)

In 1998 an estimated 564,800 Americans died from cancer. ${ }^{1}$ The deaths from breast $(43,900)$, cervical (4900), colorectal $(56,500)$, and prostatic $(39,200)$ cancers account for $26 \%$ of the total estimated cancer deaths. ${ }^{1}$ These deaths are potentially avoidable, because these cancers are amenable to early detection, and the prognosis is favorable if the patient has early treatment. For each of these cancers, there are early detection regimens supported

Submitted, revised, 11 August 1999.

From the Department of Family Medicine (MTR, DWG, BW), University of Michigan Health System, Ann Arbor. Address reprint requests to Mack T. Ruffin IV, MD, MPH, Department of Family Medicine,1018 Fuller St, Ann Arbor, MI 48109-0708.

This research was supported by the grant CA 01618 from the National Cancer Institute, Bethesda, Md. by various medical and professional organizations. In addition, a number of studies have investigated the efficacy and effectiveness of each regimen in reducing mortality from the related cancer.

The evaluation of physicians' implementation of regimens for early cancer detection has been done primarily through self-report methods. The 1984 and 1989 national survey of physicians (internists, general practitioners and family physicians, obstetricians and gynecologists) by the American Cancer Society regarding early cancer detection in asymptomatic people found that physicians placed greater emphasis on early cancer detection in 1989 compared with 1984. ${ }^{2,3}$ The greatest changes in emphasis were for early detection of breast (39\% to $61 \%$ ) and colorectal ( $31 \%$ to $40 \%$ ) cancer. More than $95 \%$ of these physicians reported ever per- 
forming digital rectal examination, breast physical examination, mammogram, Papanicolaou smear, or prostate examination on asymptomatic people. The use of stool blood test was $89 \%$, and the least frequent procedure was proctoscopic examination at $49 \%$. In contrast, the range of physicians who follow or exceed the American Cancer Society guidelines with all patients was much lower, ranging from $23 \%$ for proctoscopic examination to $78 \%$ for breast examination. Other surveys have found different levels of use for various early detection regimens. ${ }^{4-11}$ Several investigators have questioned the validity of physician self-report studies of provision of cancer prevention services. ${ }^{12,13}$

Another source of data on physicians' practice of early cancer detection is from studies using chart audits. Dietrich and Goldberg ${ }^{14}$ found no difference between generalists and subspecialists in performance of any individual prevention service, but they did note wide variation within each group. Significantly lower compliance with the regimens is found with chart audits than in the self-report data. ${ }^{15-20}$ Others have explored the practice of cancer screening among primary care practices with an intent to increase the screening rates. Three recent examples of these studies reported relatively little impact on screening rates after resource-intense interventions. ${ }^{21-23}$ The percentages of women in these studies having received screening tests for breast or cervical cancer in the past 2 years were $28 \%$ to $52 \%$ for clinical breast examination, $24 \%$ to $59 \%$ for mammogram, and $19 \%$ to $56 \%$ for Papanicolaou smears. ${ }^{21-23}$ All percentages were consistently well below the target for the year 2000 . The performance for colorectal screening tests fell substantially below the target of $40 \% .^{21-23}$ The methodologic problems associated with data from chart audits that have been previously documented ${ }^{24-26}$ need to be considered, however. Other studies ${ }^{27-30}$ have shown larger and sustained increases in the delivery of cancer preventive services. In contrast to the studies reporting minimal increase in preventive services, the studies reporting substantive increases in preventive services have been limited to either single-practice sites of highly committed practitioners ${ }^{27,28}$ observed for only a short time, such as 12 months, ${ }^{30}$ or sites that lacked community-based primary care practices ${ }^{29,31}$

In summary, certain subsets of the population are not receiving adequate early detection regimens for breast, cervical, colorectal, and prostatic cancer.
One goal of Healtby People $2000^{32}$ is to eliminate these gaps in cancer screening. One source of this problem is partially attributable to the failure of physicians and their practices to provide consistently adequate early cancer-detection regimens. Studies are lacking, however, that evaluate the delivery of screening procedures for all four of these cancers among a large sample of community-based primary care offices. Focusing on one disease or one screening test does not represent the actual setting in which physicians and patients interact with respect to early cancer detection or any medical issue. ${ }^{33,34}$ The objectives of our study were (1) to determine the current rates of screening for each of these cancers in community-based, primary care offices; and (2) to determine the patient factors that predict completion of a single cancer-screening test, of all tests for cancers that have more than one screening procedure (breast, colorectal, and prostate), and of all cancer-screening procedures for age and sex.

\section{Methods \\ Population}

Practices were recruited from the Michigan Research Network, practices previously participating in the research projects organized from the University of Michigan, practices receiving the departmental newsletter, and practices participating in an influenza-monitoring study. Practices were eligible to participate in this study if both of the following two criteria were met: (1) the practice provided nonsubspecialty care or medical care not restricted to a specific disease, organ system, or sex; and (2) the practice served adults (older than 18 years). Practices were excluded if they (1) provided primarily acute or urgent care $(50 \%$ or more of office visits) rather than continuous care, (2) excluded patients because of older age or race, (3) saw fewer than 10 patients per day more than 4 days per week, or (4) had less than $50 \%$ of the physicians in the practice agreeing to participate.

\section{Data Collection}

Medical records from 1993 to 1994 of patients from each practice were abstracted if the patient (1) was aged 40 years and older, (2) did not have cancer of any type previously diagnosed, and (3) was active in the practice (defined as having been seen at least twice in the previous 2 years). Approximately 200 
eligible charts (100 men and 100 women) were selected randomly from all available records. If a practice did not have 100 charts that met the eligibility criteria for either sex, then all eligible charts were audited.

During chart audits, the data were abstracted from only the current version of each chart using all the information in that version, including hospital notes, laboratory reports, radiologic reports, and consultation letters. The data abstracted included demographic information and completion of the specific cancer-screening procedures. The demographic variables were age, sex, year of first visit to the practice, number of visits in last 24 months, height, weight, race, marital status, smoking status, alcohol use, insurance types, and chronic illnesses or problems. For women, information was also collected on whether the patient was under the care of an outside gynecologist, had a hysterectomy, or was taking oral contraceptives or hormone replacement.

The date and results were collected for each of the cancer-screening procedures (clinical breast examination, mammogram, Papanicolaou smear, digital rectal examination, fecal occult blood test, prostate-specific antigen, and flexible sigmoidoscopy). The auditors determined whether the most recent screening procedure was part of a health maintenance examination or other type of encounter. If the patient had received more than one of any of the screening procedures, then the dates of the previous two were collected. For breast self-examination, auditors looked for any documentation of recommending, reviewing, or teaching breast selfexamination. Colonoscopies and air-contrast barium enemas were grouped with flexible sigmoidoscopies, because the study physicians would determine when and whether another imaging procedure would be recommended for screening. None of the study physicians recommended routine use of either colonoscopies or air-contrast barium enemas in screening for colorectal cancer.

\section{Analysis}

Initially we calculated frequencies and summary statistics on all variables. Age was dichotomized at 40 to 49 years vs 50 years and older. Next, bivariate associations between the screening procedure (ie, each cancer-screening test) and the age classification were determined using chi-square tests.
Screening indexes were created for each cancer that had more than one screening procedure (ie, breast, colorectal, and prostate). The breast cancer screening index that was created for each female patient consisted of any discussion of breast self-examination, a clinical breast examination ( 2 years for age $<$ 40 years; every year for age $\geq 50$ years) and a mammogram ( 2 years for age $<40$ years, every year for age $\geq 50$ years). The colorectal cancer-screening index was created for all patients aged 50 years and older and consisted of digital rectal examination in 1 year, fecal occult blood test in 1 year, and flexible sigmoidoscopy in 5 years. The prostate cancer screening index was created for men aged 50 years and older and consisted of digital rectal examination in 1 year and prostate-specific antigen test in 1 year. In a similar fashion screening indexes were created for each sex and age group $(<50$ years and $\geq 50$ years) consisting of all screening procedures relevant for age and sex (ie, women $\geq 50$ years: Papanicolaou smear in 3 years, breast selfexamination ever, a clinical breast examination in 1 year, mammogram in 1 year, digital rectal examination in 1 year, fecal occult blood test in 1 year, and flexible sigmoidoscopy in 5 years).

To explore the impact of the patient variables on completion of the screening procedures and screening indexes, we calculated bivariate associations using chi-square, $t$ tests, and Mann-Whitney $\mathrm{U}$ tests, where appropriate. Lastly, we used logistic regression analysis (using the backward stepwise procedure) to assess which combination of patient variables had the strongest effect on patient screening participation for each screening procedure individually and each screening index. We did not develop logistic models for those screening variables with less than $20 \%$ of the cases in one of the screen-no screen categories.

\section{Results}

The population of practices from which study participants were recruited consisted of 88 community-based primary care offices. After the recruitment effort was completed, 30 practices were eligible and agreed to participate in the study. Of the remaining 58 practices, 5 were not eligible (all provided only urgent care), 5 were no longer in practice or had moved their practice, 5 declined to participate, and 33 did not respond to any of the recruitment contacts. Of the 30 practices agreeing 
to participate, 6 did not allow data collection to be completed. The data reported represent 24 community-based primary care practices.

The 24 practices were equally distributed between urban and rural location and small ( 3 or fewer providers) and large (more than 3 providers). No significant relation existed between the size of practice as measured by number of providers and rural or urban location. The mean opening year of the practices was 1984 , and there was no difference between rural and urban or small and large practices.

The charts of 5125 patients were audited. The demographic features of these patients are displayed in Table 1. Among women aged 40 to 49 years compared with women 50 years and older, a significantly higher proportion used an outside gynecologist $(16 \%$ vs $11 \%, P<.0001)$, a lower proportion reported a hysterectomy ( $22 \%$ vs $29 \%, P<$ $.0001)$, a higher proportion used oral contraceptive use $(7 \%$ vs $1 \%, P<.0001)$, and a lower proportion used hormone replacement therapy ( $19 \%$ vs $35 \%$, $P<.0001)$. Differences between rural and urban practices were significant on only a few demographic variables. Rural practices had significantly more charts with no race identification $(41.1 \%$ vs $34.0 \%, P=.00001$ ), a lower proportion of patients insured through managed health care $(22.5 \%$ vs $39.3 \%, P=.00001)$, fewer charts documenting alcohol use $(47.4 \%$ vs $60 \%, P=.00001)$, fewer charts documenting patient use of a gynecologist (6.6\% vs $20.4 \%, P=.00001)$, and higher patient use of estrogen replacement $(31.9 \%$ vs $25.3 \%, P=$ $.0003)$. Small practices ( 3 or fewer providers) had significantly more charts with no race identification (49.8\% vs $26.6 \%, P=.00001$ ), a lower proportion of patients insured through managed health care (22.9\% vs $37.8 \%, P=.00001)$, and fewer charts with documented alcohol use (48\% vs $58.5 \%, P=$ .0001).

Displayed in Figure 1 are the proportion of women's charts with documentation that each individual procedure was done within the defined time interval, stratified by the age groups of 40 to 49 and 50 and older. Logistic regression models were developed for each of the following outcomes: Papanicolaou smear in last 3 years, self-breast examination reviewed ever, clinical breast examination in last year and 2 years, mammogram in the last year and 2 years. The odds ratio for the significant predictors in each logistic regression model
Table 1. Demographic Features of Patients from 5125 Chart Audits.

\begin{tabular}{|c|c|}
\hline Variable & Value \\
\hline Age (mean years) & 55 \\
\hline \multicolumn{2}{|l|}{ Race (\%) } \\
\hline White & 60 \\
\hline Other & 2 \\
\hline Unknown & 38 \\
\hline Sex (\% women) & 50 \\
\hline \multicolumn{2}{|l|}{ Marital status (\%) } \\
\hline Married & 73 \\
\hline Single, widowed, separated & 20 \\
\hline \multicolumn{2}{|l|}{ Insurance status (\%) } \\
\hline Health maintenance organization & 30 \\
\hline Other private & 49 \\
\hline Medical, Medicaid & 16 \\
\hline None & 2 \\
\hline \multicolumn{2}{|l|}{ Smoking status (\%) } \\
\hline Current & 20 \\
\hline Never & 45 \\
\hline Former & 18 \\
\hline Not documented & 18 \\
\hline Body mass index $\left(\mathrm{kg} / \mathrm{m}^{2}\right)$ (mean) & 28.3 \\
\hline Years as a patient (mean) & 5.3 \\
\hline Visits in past 24 months (No.) & 6.3 \\
\hline \multicolumn{2}{|l|}{ Alcohol use (\%) } \\
\hline Yes & 37 \\
\hline None & 32 \\
\hline Not documented & 31 \\
\hline Chronic medical problems (\% none) & 78.2 \\
\hline \multicolumn{2}{|l|}{ Women's issues } \\
\hline Currently use estrogen (\%) & 27 \\
\hline Currently use oral contraceptives (\%) & 3 \\
\hline \multicolumn{2}{|l|}{ See a gynecologist $(\%)$} \\
\hline Yes & 9 \\
\hline No & 62 \\
\hline Not documented & 29 \\
\hline \multicolumn{2}{|l|}{ Have had a hysterectomy (\%) } \\
\hline Yes & 24 \\
\hline No & 66 \\
\hline Not documented & 10 \\
\hline
\end{tabular}

Note: some variables total less than $100 \%$ because of missing data.

are summarized in Table 2. Possible variables considered in each model, but not found to be significant predictors, were number of chronic problems, body mass index, smoking status, alcohol use, years as a patient in the practice, and race.

The proportion of women aged 40 to 49 years with documentation of breast self-examination discussion ever, clinical breast examination in the past 


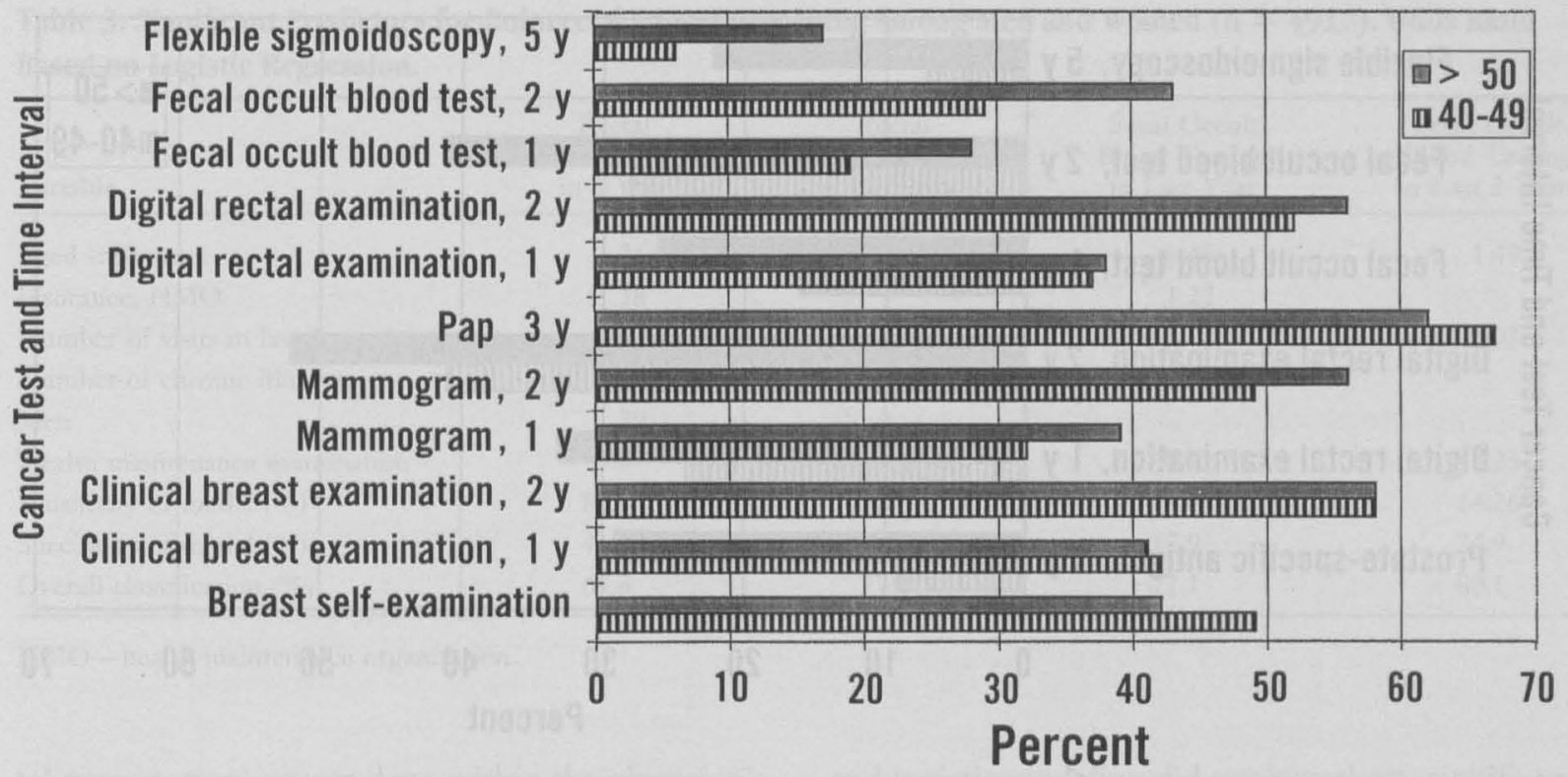

Figure 1. Proportion of women receiving individual screening procedure within a defined time interval by agegroup. Significant differences $(P<.0001)$ exist between age groups for self-breast examination review ever, mammogram in 1 year or 2 years, fecal occult blood test in 1 year or 2 years, and flexible sigmoidoscopy in 5 years.

2 years, and mammography in the past 2 years was $29 \%$. The proportion of women aged 50 years and older with documentation of breast self-examination discussion ever, clinical breast examination in the past year, and mammography in the past year was $17 \%$. The proportion of women aged 50 years and older with a digital rectal examination in the past year, fecal occult blood test in the past year, and flexible sigmoidoscopy in the past 5 years was $5.8 \%$. Only $8.6 \%$ of women aged 40 to 49 years had documentation of their receiving a Papanicolaou smear in the past 3 years (with an intact cervix), breast self-examination discussion ever, clinical breast examination in the past year, and

Table 2. Significant Predictors for Cancer Test Among Women $(\mathrm{n}=\mathbf{2 2 2 8})$. Odds Ratios Based on Logistic Regression.

\begin{tabular}{|c|c|c|c|c|c|c|}
\hline Variable & $\begin{array}{l}\text { Papanicolaou } \\
\text { Smear in } \\
\text { Last } 3 \text { Years }\end{array}$ & $\begin{array}{c}\text { Breast } \\
\text { Self-Examination } \\
\text { Review Ever* }\end{array}$ & $\begin{array}{l}\text { Clinical Breast } \\
\text { Examination } \\
\text { in Last Year }\end{array}$ & $\begin{array}{l}\text { Clinical Breast } \\
\text { Examination } \\
\text { in Last } 2 \text { Years }\end{array}$ & $\begin{array}{l}\text { Mammogram in } \\
\text { Last Year }\end{array}$ & $\begin{array}{c}\text { Mammogram in } \\
\text { Last } 2 \text { Years }\end{array}$ \\
\hline Aged $\geq 50$ years & .64 & .78 & & & & 1.40 \\
\hline Hormone replacement & 2.15 & 1.56 & 1.69 & 2.25 & 1.88 & 2.46 \\
\hline Insurance, HMO & 1.49 & 1.63 & $x^{2}=$ & 1.35 & 1.56 & 1.65 \\
\hline $\begin{array}{l}\text { Number of visits in last } \\
2 \text { years }\end{array}$ & 1.03 & 8 & $4=$ & 1.02 & 1.02 & 1.03 \\
\hline Years as patient & & 1.03 & & & & \\
\hline Married & & & & 1.29 & 1.30 & 1.05 \\
\hline $\begin{array}{l}\text { Health maintenance } \\
\text { examination }\end{array}$ & 28.53 & & 10.02 & 18.97 & 5.09 & 10.06 \\
\hline Sensitivity of model (\%) & 81.6 & 42.5 & 56.3 & 72.6 & 80.9 & 78.0 \\
\hline Specificity of model (\%) & 86.4 & 71.7 & 89.2 & 88.3 & 50.0 & 74.5 \\
\hline Overall classification (\%) & 84.7 & 58.5 & 69.7 & 81.8 & 69.8 & 76.2 \\
\hline
\end{tabular}

HMO - health maintenance organization.

* Data not collected to determine whether breast self-examination review or education given as part of a health maintenance examination or other type of encounter. 


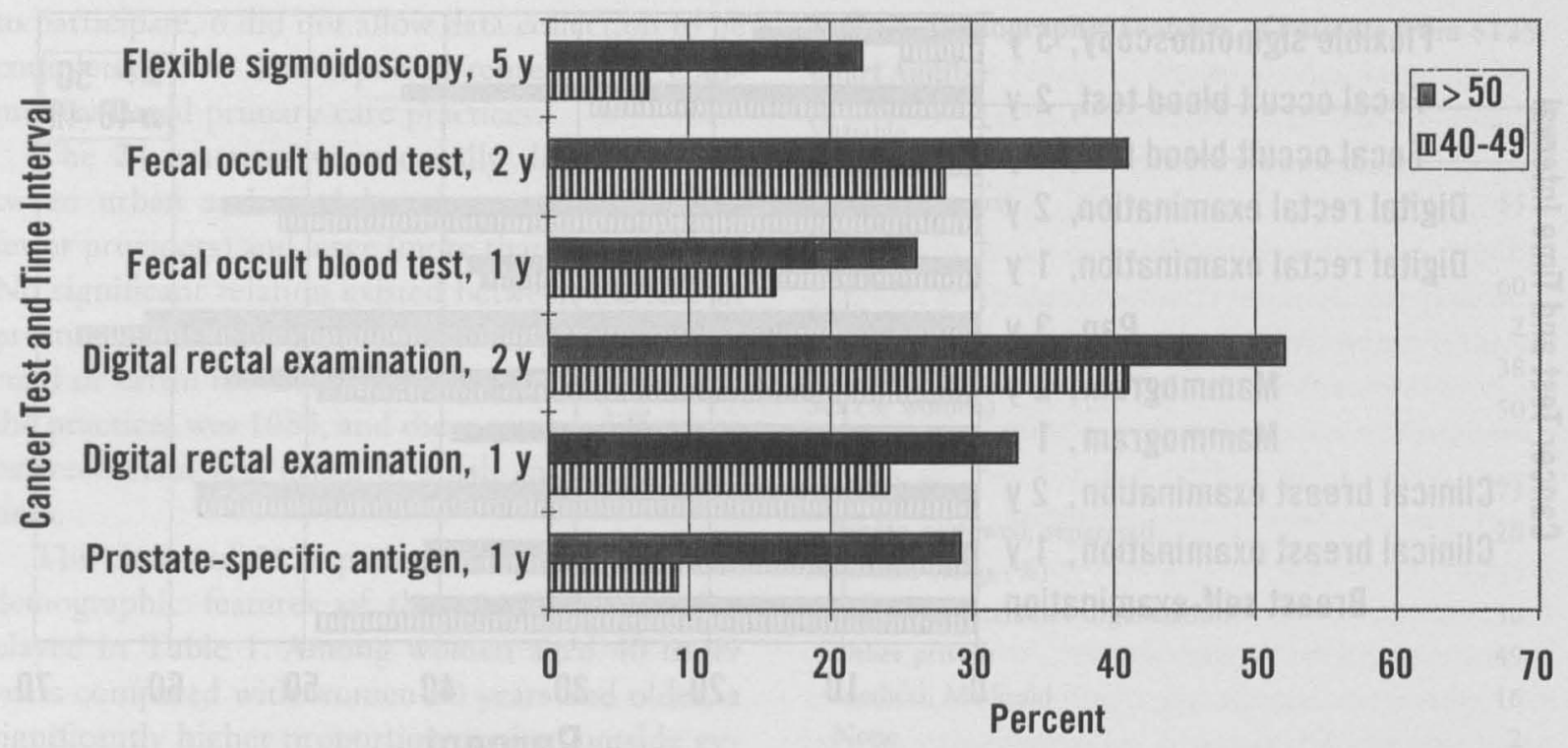

Figure 2. Proportion of men receiving individual screening procedure within a defined time interval by age-group. Significant differences $(P<.0001)$ exist between age groups for prostate-specific antigen test in 1 year, digital rectal examination in 1 year and 2 years, fecal occult blood test in 1 year or 2 years, and flexible sigmoidoscopy in 5 years.

mammography in the past 2 years (or all cancerscreening procedures for their age and sex). Only $3 \%$ of women aged 50 years and older had documentation of receiving a Papanicolaou smear in the past 3 years (with an intact cervix), breast selfexamination discussion ever, a clinical breast examination in the past year, a mammography in the past year, a digital rectal examination in the past year, a fecal occult blood test in the past year, and a flexible sigmoidoscopy in the past 5 years (or all cancerscreening procedures for their age and sex). These proportions were so small that we could not develop logistic regression models.

Displayed in Figure 2 are the proportion of men's charts with documentation that each individual procedure was done within the defined time interval by age groups of 40 to 49 years and 50 years and older. The proportion of men receiving a prostate-specific antigen test in the past year did not meet our criteria for logistic regression analysis. The proportion of men aged 50 years and older having had a digital rectal examination in the past year and a prostate-specific antigen test was $4.3 \%$. The proportion of men aged 50 years and older having had a digital rectal examination in the past year, fecal occult blood test in the past year, and flexible sigmoidoscopy in the past 5 years was $5 \%$. Only $5 \%$ of men 50 years and older had documen- tation of receiving a digital rectal examination in the past year, a fecal occult blood test in the past year, a flexible sigmoidoscopy in the past 5 years, and a prostate-specific antigen test in the last year (or all cancer-screening procedures for their age and sex). The proportion of men completing all cancer-screening procedures for colorectal cancer, prostatic cancer, and both was so small that we could not develop logistic regression models.

No significant differences existed between men and women in the same age-group on colorectal cancer screening procedures. Logistic regression models for digital rectal examination in the last year and last 2 years, along with fecal occult blood testing within 1 year and 2 years, are summarized in Table 3. The proportion of men and women getting a flexible sigmoidoscopy did not meet our criteria for logistic regression analysis.

\section{Discussion}

The single most consistent predictor of documented cancer screening among men and women aged 40 years and older seen in primary care settings was the patient coming in for a health maintenance visit. This was found to be true regardless of whether the screening test was part of the examination (clinical breast examination and digital rec- 
Table 3. Significant Predictors for Colorectal Cancer Screening Among Men and Women $(n=4917)$. Odds Ratio Based on Logistic Regression.

\begin{tabular}{|c|c|c|c|c|}
\hline Variable & $\begin{array}{c}\text { Rectal } \\
\text { Examination } \\
\text { in } 1 \text { Year }\end{array}$ & $\begin{array}{c}\text { Rectal } \\
\text { Examination } \\
\text { in } 2 \text { Years }\end{array}$ & $\begin{array}{l}\text { Fecal Occult } \\
\text { Blood Testing } \\
\text { in Last Year }\end{array}$ & $\begin{array}{l}\text { Fecal Occult } \\
\text { Blood Testing } \\
\text { in Last } 2 \text { Years }\end{array}$ \\
\hline Aged $\geq 50$ years & 1.26 & 1.26 & 1.45 & 1.49 \\
\hline Insurance, $\mathrm{HMO}$ & 1.38 & & 1.22 & \\
\hline Number of visits in last 2 years & & 1.02 & 1.02 & 1.03 \\
\hline Number of chronic illnesses & 1.28 & & & \\
\hline Men & .79 & & & \\
\hline Health maintenance examination & 5.9 & 11.43 & 8.42 & 14.26 \\
\hline Sensitivity of model (\%) & 81.6 & 76.0 & 8.41 & 14.26 \\
\hline Specificity of model (\%) & 46.7 & 78.4 & 17.9 & 74.9 \\
\hline Overall classification (\%) & 69.8 & 77.2 & 77.1 & 80.1 \\
\hline
\end{tabular}

HMO-health maintenance organization.

tal examination) or was done within the physician's office at the time of the visit (prostate-specific antigen), or whether the patient was referred to another site (mammogram). This finding was true regardless of whether the patient was seen in a rural or urban site practice or the patient was seen in a large practice (more than 3 providers) or small practice (3 or fewer providers). It was true for well-accepted procedures (Papanicolaou smears, mammograms in women aged 50 years and older) and for controversial procedures (prostate-specific antigen test). For each screening procedure, other variables also made significant contributions in predicting documentation of receiving the test.

Among women, the other variables that contributed to the logistic regression models were age, hormone replacement therapy, insurance type, number of visits in the last 2 years, years as a patient, and marital status. The nature of the relations was as most physicians would predict. Variables of interest with no apparent relation to documentation of receiving a cancer-screening procedure were race, smoking status, number of chronic illnesses, alcohol use, and body mass index. Even after considering all these variables, it was still impossible to determine significant predictors of women getting sigmoidoscopy, all screening procedures for breast and colorectal cancers, or all procedures for age. So few women have documentation of all cancer-screening procedures relevant to their age that bivariate analysis and logistic modeling either could not be done, or they revealed insignificant predictors. This issue was even more pronounced among men, because bivariate analysis and logistic modeling did not reveal any significant difference among men getting prostate-specific antigen tests, sigmoidoscopy, or all screening procedures for colorectal cancer, or all tests relevant for age.

With respect to cancer-screening procedures relevant to both women and men, there were similar findings of other variables contributing to logistic regression models. These included age, insurance type, number of visits in last 2 years, and marital status. The only difference between the sexes was that men were less likely than women to get a rectal examination in the past year. This finding is somewhat difficult to explain given the dual possible reasons for digital rectal examinations among men (colorectal and prostatic cancer). Women might more routinely receive a rectal examination, however, as part of the requested Papanicolaou and pelvic examination.

There are several limitations to these findings. First, charts audits were used as the source of demographic and cancer-screening data. Some would argue that some screening is occurring that was not captured by this data source. For example, women could be obtaining Papanicolaou smears, breast examinations, and even mammograms in settings other than their primary care office, such as by gynecologists. Our data suggest, however, that the proportion of women getting care at sites other than their primary care offices is extremely small (only $9 \%$ were documented as seeing a gynecologist) and would have very little impact on the conclusions. 
Second, the population of these practices contained minimal numbers of minorities. Thus, our insights are not generalizable to practices with more diverse patient populations. Third, the findings of this study depend on the beliefs of the physicians regarding cancer-screening intervals and specific procedures. The consensus of the study physicians was to follow the American Cancer Society 1993-94 guidelines. No practice had written or documented policies or protocols for cancer screening, however. In addition, with each office beliefs varied among physicians and staff regarding specific screening procedures and intervals. Thus, these findings might not generalize to other groups of physicians who have different beliefs.

Fourth, the variables considered in this study reflect only one sphere of influence over behavior-the patient. Other possible spheres of influence $^{33}$ include the patient's environment, the physician (beliefs, knowledge, priorities, and attitudes), and the physician's environment. Because we addressed only a limited number of variables in this study, it is not possible to gain complete insight into all the influences on behavior.

As noted by Preisser and colleagues, ${ }^{35}$ fewer than one third of patients older than 40 years have annual health maintenance examinations. Yet, this annual examination is the single most influential predictor of getting individual cancer-screening procedures. Even so, it does not explain why so few men and women have received all the cancerscreening procedures relevant to their age. Yet, the promotion of an annual visit to a health care provider to focus of preventive services is likely to increase the screening recommendations provided to patients and subsequent delivery of preventive services. It still remains unclear which interventions are successful in increasing the proportion of a primary care practice that will regularly request such a visit.

In general, our understanding of physician's behaviors can best be described as a black box. There are numerous theories, ${ }^{33,34,36-39}$ physician-described barriers and facilitators, ${ }^{40-45}$ and many proposed tools to change physician practices $^{20,21,46-55}$ There is, however, inadequate indepth analysis of physician practices, especially that focused on preventive services including all relevant spheres of influence. As a result, investigators are beating on a black box (physician behavior) with a variety of tools to modify the delivery of preven- tive services. The result is only marginal changes or no change. Before we can intervene successfully in physician behavior, we need a far more basic understanding of physician's practice behaviors.

\section{References}

1. Landis SH, Murray T, Bolden S, Wingo PA. Cancer statistics, 1998. CA Cancer J Clin 1998;48:6-29.

2. 1989 survey of physicians' attitudes and practices in early cancer detection. CA Cancer J Clin 1990;40: 77-101.

3. Survey of physicians' attitudes and practices in early cancer detection. CA Cancer J Clin 1985;35:197213.

4. Warner SL, Worden JK, Solomon LJ, Wadland WC. Physician interest in breast cancer screening education. A survey of Vermont family physicians. J Fam Pract 1989;29:281-5.

5. Cummings KM, Mettlin C, Lazar L, Frisof KB. Family physicians' beliefs about cancer screening tests. Prog Clin Biol Res 1983;130:361-8.

6. Cummings KM, Funch DP, Mettlin C, Jennings E. Family physicians' beliefs about breast cancer screening by mammography. J Fam Pract 1983;17: 1029-34.

7. Battista RN, Palmer CS, Marchand BM, Spitzer WO. Patterns of preventive practice in New Brunswick. Can Med Assoc J 1985;132:1013-5.

8. Battista RN, Spitzer WO. Adult cancer prevention in primary care: contrasts among primary care practice settings in Quebec. Am J Public Health 1983; 73:1040-1.

9. Bergner M, Allison CJ, Diehr P, Ford LG, Feigl P. Early detection and control of cancer in clinical practice. Arch Intern Med 1990;150:431-6.

10. Gemson DH, Elinson J. Prevention in primary care: variability in physician practice patterns in New York City. Am J Prev Med 1986;2:226-34.

11. Rosen MA, Logsdon DN, Demak MM. Prevention and health promotion in primary care: baseline results on physicians from the INSURE Project on Lifecycle Preventive Health Services. Prev Med 1984;13:535-48.

12. Montano DE, Phillips WR. Cancer screening by primary care physicians: a comparison of rates from physician self-report, patient survey, and chart audit. Am J Public Health 1995;85:795-800.

13. Gordon NP, Hiatt RA, Lampert DI. Concordance of self-reported data and medical record audit for six cancer screening procedures. J Natl Cancer Inst $1993 ; 85: 566-70$.

14. Dietrich AJ, Goldberg H. Preventive content of adult primary care: do generalists and subspecialists differ? Am J Public Health 1984;74:223-7.

15. Woo B, Woo B, Cook EF, Weisberg M, Goldman L. Screening procedures in the asymptomatic adult. Comparison of physicians' recommendations, pa- 
tients' desires, published guidelines, and actual practice. JAMA 1985;254:1480-4.

16. McPhee SJ, Richard RJ, Solkowitz SN. Performance of cancer screening in a university general internal medicine practice: comparison with the 1980 American Cancer Society Guidelines. J Gen Intern Med 1986;1:275-81.

17. Romm FJ. The periodic health examination in a family practice center: use, content, and results. Fam Pract Res J 1987;7:69-77.

18. Ellsbury KE, Montano DE, Parker JJ Jr. Preventive services in a hybrid capitation and fee-for-service setting. J Fam Pract 1989;28:540-4.

19. Ornstein SM, Garr DR, Jenkins RG, Rust PF, Zemp L, Arnon A. Compliance with five health promotion recommendations in a university-based family practice. J Fam Pract 1989;29:163-8.

20. Osborn EH, Bird JA, McPhee SJ, Rodnick JE, Fordham D. Cancer screening by primary care physicians. Can we explain the differences? J Fam Pract 1991;32:465-71.

21. Manfredi C, Czaja R, Freels S, Trubitt $M$, Warnecke $\mathrm{R}$, Lacey L. Prescribe for health. Improving cancer screening in physician practices serving low-income and minority populations. Arch Fam Med 1998;7: 329-37.

22. Dietrich A, Tobin JN, Sox CH, et al. Cancer earlydetection services in community health centers for the underserved. A randomized controlled trial. Arch Fam Med 1998;7:320-7.

23. Williams RB, Boles $M$, Johnson RE. A patient-initiated system for preventive health care. A randomized trial in community-based primary care practices. Arch Fam Med 1998;7:338-45.

24. Tufo HM, Speidel JJ. Problems with medical records. Med Care 1971;9:509-17.

25. Wu L, Ashton CM. Chart review. A need for reappraisal. Eval Health Prof 1997;20:146-63.

26. Ruffin MT 4th. Can we change physicians' practices in the delivery of cancer-preventive services? Arch Fam Med 1998;7:317-9.

27. Cooley KA, Frame PS, Eberly SW. After the grant runs out. Long-term provider health maintenance compliance using a computer-based tracking system. Arch Fam Med 1999;8:13-7.

28. Frame P, Zimmer JG, Werth PL, Hall WJ, Eberly SW. Computer-based vs manual tracking health maintenance tracking. A controlled trial. Arch Fam Med 1994;3:581-8.

29. McPhee SJ, Bird JA, Jenkins CN, Fordham D. Promoting cancer screening. A randomized, controlled trial of three interventions. Arch Intern Med 1989; 149:1866-72.

30. McPhee SJ, Bird JA, Fordham D, Rodnick JE, Osborn EH. Promoting cancer prevention activities by primary care physicians. Results of a randomized, controlled trial. JAMA 1991;266:538-44.

31. Harris RP, O'Malley MS, Fletcher SW, Knight BP.
Prompting physicians for preventive procedures: a five-year study of manual and computer reminders. Am J Prev Med 1990;6:145-52.

32. Healthy people 2000: national health promotion and disease prevention objectives for the year 2000. MMWR Morb Mortal Wkly Rep 1990;39:689-90, 695-7.

33. Pommerenke FA, Dietrich A Improving and maintaining preventive services. Part 1: applying the patient model. J Fam Pract 1992;34:86-91.

34. Pommerenke FA, Dietrich A. Improving and maintaining preventive services Part 2: practical principles for primary care. J Fam Pract 1992;34:92-7.

35. Preisser JS, Cohen SJ, Wofford JL, et al. Physician and patient predictors of health maintenance visits. Arch Fam Med 1998;7:346-51.

36. Phillips KA, Morrison KR, Andersen R, Aday LA. Understanding the context of healthcare utilization: assessing environmental and provider-related variables in the behavioral model of utilization. Health Serv Res 1998;33(3 Pt 1):571-96.

37. Pommerenke F. Implementing preventive services: practical strategies for primary care physicians. Cancer Prev 1992;3:1-13.

38. Dietrich AJ, Kotrady KP. Procedures in family practice. What's best for your patients and for you. Arch Fam Med 1993;2:1028-30.

39. Dietrich AJ, Barrett J, Levy D, Carney-Gersten P. Impact of an educational program on physician cancer control knowledge and activities. Am J Prev Med 1990;6:346-52.

40. Orlandi MA. Promoting health and preventing disease in health care settings: an analysis of barriers. Prev Med 1987;16:119-30.

41. Graham R,. Mansfield CM. Motivation and barriers for the primary care physician. Cancer 1988; 61(Suppl):2401.

42. Frame PS. Health maintenance in clinical practice: strategies and barriers. Am Fam Physician 1992;45: 1192-1200.

43. Costanza ME, Stoddard AM, Zapka JG, Gaw VP, Barth R. Physician compliance with mammography guidelines: barriers and enhancers. J Am Board Fam Pract 1992;5:143-52.

44. Williams PA, Williams $M$. Barriers and incentives for primary care physicians in cancer prevention and detection. Cancer 1988;61(11 Suppl):2382-90.

45. Rimer B, Engstrom PF, Keintz MK, Myers RE, Rosan J. Barriers and facilitators to compliance with routine mammographic screening. Prog Clin Biol Res 1989;293:125-33.

46. Cohen SJ, Halvorson HW, Gosselink CA. Changing physician behavior to improve disease prevention. Prev Med 1994;23:284-91.

47. Lungberg GD. Changing physician behavior in ordering diagnostic tests. JAMA 1998;280:2036.

48. Thompson RS, Kirz HL, Gold RA. Changes in phy- 
sician behavior and cost savings associated with organizational recommendations on the use of "routine" chest $\mathrm{x}$ rays and multichannel blood tests. Prev Med 1983;12:385-96.

49. Bird JA, McPhee S, Jenkins C, Fordham D. Three strategies to promote cancer screening. How feasible is wide-scale implementation? Med Care 1990;28: $1005-12$.

50. Costanza ME, Zapka JG, Harris DR, et al. Impact of a physician intervention program to increase breast cancer screening. Cancer Epidemiol Biomarkers Prev 1992;1:581-9.

51. Clementz GL, Aldag JC, Gladfelter TT, Barclay AM, Brooks HF. A randomized study of cancer screening in a family practice setting using a recall model. J Fam Pract 1990;30:537-41.
52. Epps RP. Can we change physicians' practices in the delivery of cancer-preventive services.. Arch Fam Med 1998;7:315-6.

53. McPhee SJ, Bird JA, Jenkins CN, Fordham D. Promoting cancer screening. A randomized, controlled trial of three interventions. Arch Fam Med 1989;149: 1866-72.

54. Yarnall KS, Rimer BK, Hynes D, et al. Computerized prompts for cancer screening in a community health center. J Am Board Fam Pract 1998;11:96104.

55. Ornstein SM, Garr DR, Jenkins RG, Rust PF, Arnon A. Computer-generated physician and patient reminders. Tools to improve population adherence to selected preventive services. J Fam Pract 1991;32:82-90. 